\title{
School children's use of digital devices, social media and parental knowledge and involvement - the case of Abu Dhabi
}

\author{
Masood Badri ${ }^{1}$ - Ali Alnuaimi ${ }^{1}$ - Asma Al Rashedi ${ }^{1}$. \\ Guang Yang $^{1} \cdot$ Khaled Temsah $^{2}$
}

Published online: 10 December 2016

(C) The Author(s) 2017. This article is published with open access at Springerlink.com

\begin{abstract}
This paper looks at the usage of social media devices and applications, and parental knowledge and involvement among Abu Dhabi children in Grade 6 or higher. It examines the young children's usage of personal computers, mobile phones and tablet PCs, and social media related apps. The paper tries to understand the reasons for joining or not joining online social networking. It explores the parental knowledge of such activities and their chance of being invited to join their children's' social networking groups. More than 31,000 children from private and public schools participated in the online survey. Results show a high home access to the Internet of $91.7 \%$. Children reported using social networks mainly for keeping in touch with family and friends, and to find information. Most of the children reported that their parents were aware of their online social networking activities (82.2\%). About $38.7 \%$ said that their parents were in their friend group on online social networking. There is negative correlation between time spent on social networks and
\end{abstract}

Masood Badri

masood.badri@adec.ac.ae

Ali Alnuaimi

Alnuaimi@adec.ac.ae

Asma Al Rashedi

asma.alrashedi@adec.ac.ae

Guang Yang

Guang.yang@adec.ac.ae

Khaled Temsah

Khaled.Temsah@moe.gov.ae

1 Abu Dhabi Education Council, Abu Dhabi, United Arab Emirates

2 Ministry of Education, Dubai, United Arab Emirates 
perceived student performance in specific subjects. The paper also discusses gender, grade (or age), and school type and implications.

Keywords Social media $\cdot$ Social networking $\cdot$ Parental knowledge $\cdot$ School children $\cdot$ Abu Dhabi

\section{Introduction}

There is increasing evidence that the amount of time children are spending on technological devices and social media at home and in school has raised concerns on the impact of these activities on their development (Goh et al. 2015; Kanthawongsa and Kanthawongs 2013). Surveys conducted on parents suggest that many buy home computers and subscribe to get Internet access to provide their children with educational resources (Turow 1999; DeBell and Chapman 2003; Greenfield and Yan 2006; Livingstone and Haddon 2008; Henderson 2011). In addition, research points out that the use of social media among children has increased extensively (Rosen et al. 2014; Willett 2015). Wilson et al. (2005) show that children's susceptibility to media influence can vary according to their gender and age, and they conclude with guidelines to help parents enhance the positive effects of the media while minimizing the risks associated with certain types of content. In Abu Dhabi, El Khouli (2013) stressed the necessity of participation of family in the monitoring of these negatives aspects of social networking for families. In its recent report, the Global Mideast Insight (2016) cited that social media in the Emirates has use in communication, connecting with friends, family or similarly inclined individuals, as a news source and even to organize large events. For some small to medium business owners it is their entire advertising platform.

The current study must be considered as an initial exploration of the complex dynamics of social media use among Abu Dhabi children. It will provide a current, comprehensive and accurate account of social networking practices as well as the parental involvement and know-how of their children's engagement in such activities.

\section{Literature review}

\subsection{Uses of digital devices among children}

Children use home computers for various purposes (e.g., game playing and web surfing) and school work (Pew Internet and American Life Project 2002; Shields and Behrman 2000; Subrahmanyam et al. 2000). DeBell and Chapman (2003) from the National Center for Education Statistics found that $23 \%$ of children in nursery school use the Internet, where the most popular uses belonged to children 5-9 years old. Results showed that about $20.5 \%$ spent their time playing games, while $11.7 \%$ of their time was spent on homework. Roberts et al. (2005) highlighted that 8-10 year olds are the most likely of all age groups to have a video gaming device in the bedroom, spending about $1 \mathrm{~h}$ /day playing games. On the other hand, young children under the 
age of 3 or 4 years old are more likely to use the Internet to watch video clips (Childwise 2012; Findahl 2012; Teuwen et al. 2012).

\subsection{Children time and uses of social networks and their academic performance}

There are many surveys that studied the impact of time spent on social media on academic performance., we conducted a survey of business students at a large state university. Paul et al. (2012) used structural equation modeling to show statistically significant negative relationship between time spent by students on online social networks and their academic performance. Kirschner and Karpinski (2010) concluded that use of Facebook negatively affects GPA and study time spent per week. Karpinski et al. (2013) used regression analysis to show that time spent on social media (minutes/ day) was negatively predictive of overall GPA.

\subsection{Children's perceived effects of using digital devices}

Yan (2005) revealed that 5-8 year olds had only minimal or partial technical and social understanding of the Internet as compared to older children. Children thought that the Internet helped them in learning and did not have a negative influence. In contrast, older children in the 9-11 age group knew that the Internet can help in school work but that it can also give rise to bad ideas. According to the Australian Bureau of Statistics (2012), $79 \%$ of Australian children aged between 5 and 8 years old go online daily. Young children make up a substantially large user group for mobile technologies, using the Internet from a variety of devices such as touchscreen computer tablets, e-readers, laptops and smart toys (Ofcom 2012).

\subsection{Children's use of social networking}

Children may not fully understand the possible repercussions of Internet use and are at some risk as they navigate and experiment with social media (O'Keeffe and Clarke-Pearson 2011). Concerns have been expressed about the amount of time teens spend online (Gross 2004), and lack of parental control over their Internet use (Wang et al. 2005).

\subsection{Parental involvement and attitudes towards young children's usage}

Wang et al. (2005) suggest that parental awareness of and involvement in their children's Internet use is increasing; and given the risks, teens derive many benefits and gratifications from Internet use. Children usually use social networking without guidance or effective control, and this in turn reflects the challenges that have negative effects on family stability (Haythornthwaite 2005). Dodge et al. (2011) found that increasing numbers of young children are using the Internet without adult supervision at least some of the time. However, there is some evidence that indicates that Dutch parents have reported being actively involved in supervising their young children's Internet use, with children from higher socioeconomic backgrounds receiving slightly more 
supervision than those from poorer families (Nikken and Jansz 2011). Davies and Gentle (2012) noted that changes in media choices of school-age children seem to indicate a greater autonomy granted by parents in decision-making.

\subsection{Perceived differences among children}

The sites most popular with teenagers and young adults of both genders (as of 2014) are Facebook and Twitter, which constitute social network sites according to the three criteria articulated by Boyd and Ellison (2007) and Lenhart et al. (2015). However, girls on average spend more time on social network sites and use them more actively than boys (Brenner 2012; Rideout et al. 2010). This includes more girls than boys using Facebook and Twitter. Gender differences are also present in the ways teens use the Internet and social media, although usage patterns have shifted over time. Gross (2004) found that the most common activity among American middle- and high-school students was chatting via instant messaging. In 2007, teenage girls in the US were more active bloggers than boys. Boys, meanwhile, were more likely to upload online videos and use video sharing applications (Lenhart et al. 2007). Boys spend more time using computers, especially playing video games and visiting video websites such as YouTube (Rideout et al. 2010). However, girls create and share more video links (Lenhart 2012), and also are more likely to video chat, in keeping with their more active texting and mobile communication behaviors (Lenhart et al. 2010). Regardless of gender, most teens in the US today spend part of their leisure time online visiting social media sites (Pew Internet and American Life Project 2011).

Some studies indicated that gender has little impact on these interactions. Bergin (1993) found almost no gender differences among kindergarten children in computer use. Yelland (1994) concluded that, although initially boys were able to work faster and more efficiently than the girls, after a period of time, the girls did appear to perform better than boys. A study by Heft and Swaminathan (2002) found that there were gender variations in terms of the frequency of computer use, with boys using the computer more often than girls.

According to Holloway et al. (2013), the large increase in Internet and technology usage by very young children has not yet been matched by sufficient studies exploring the risks and benefits of their online interactions and use of devices.

Cranmer et al. (2009) drew similar conclusions as Dodge et al. (2011) in that Internet safety in the minds of their sample of children aged between 7 and 11 years old was an abstract and poorly understood concept. The issue of age needs to be recognized as a critical influence on the technological needs, uses and interests of children and young people (Holloway et al. 2013).

In Singapore, while there were studies of children's Internet use, these studies focused on children between the ages of 12 and 18 years (Liau et al. 2005; Mythily et al. 2008). About $85 \%$ of households in Singapore had Internet access (InfoComm Development Authority of Singapore 2010).

Given the different results from these studies, it is imperative that any study on computer and technology usage examine gender variations in Abu Dhabi. 
This paper addresses a need in the research to study Internet use among school children and to examine the extent of parental monitoring regarding children's use of digital devices and online social networking applications and tools.

\section{Research methodology}

\subsection{Participants}

The participants were students attending public or private schools in Abu Dhabi. An online survey was used to collect the data. Relative to the face-to-face process, the online process allowed for reaching of more students and more locations. A letter from the Abu Dhabi Education Council (ADEC) Research Office went to all school principals urging them to encourage students to go to the ADEC homepage and participate in the survey. The survey announcement was online for the month of January 2016. A total of 31,109 students participated in the survey. Student ages ranged from 8 to 19 years old, and students were from Grade 6 to Grade 12. Forty-one per cent were boys and $59 \%$ girls. There were 59 boys (51\%) and 57 girls (49\%). About $72.1 \%$ of the students came from private schools, while only $27.9 \%$ of the students were from public schools. Students were 18.1\% Grade 6, $17.8 \%$ Grade 7, $18.1 \%$ Grade 8, $17.6 \%$ Grade 9, $10.4 \%$ Grade 10, $9.0 \%$ Grade 11, and $5.4 \%$ Grade 12. Students from a total of 270 school participated.

The Abu Dhabi is made up of three zones, Abu Dhabi, Al Ain, and Al Gharbia. Abu Dhabi is the capital with a cosmopolitan flavor. Al Ain, is the second largest city in the Emirate of Abu Dhabi. It holds many of the emirate's greatest cultural assets relating to the national population's Bedouin roots and culture. Al Gharbia is characterized by a large geographic spread and low population density, with the highest concentrations in Madinat Zayed and Ruwais. Table 1 provides a summary of schools and students in each of the three zones.

\subsection{Objectives and procedures}

All schools in Abu Dhabi were invited to participate. The letter from ADEC to schools sought the permission of the school principals. An SMS was also

Table 1 Summary statistics of the Abu Dhabi Education Zones

\begin{tabular}{|c|c|c|c|c|}
\hline & \multicolumn{2}{|l|}{ Public } & \multicolumn{2}{|l|}{ Private } \\
\hline & Schools & Students & Schools & Students \\
\hline Abu Dhabi & 116 & 67,178 & 122 & 172,444 \\
\hline Al Ain & 103 & 56,271 & 59 & 64,999 \\
\hline Al Gharbia & 31 & 9703 & 11 & 9903 \\
\hline Total & 250 & 123,252 & 192 & 247,346 \\
\hline
\end{tabular}


addressed to all parents seeking their cooperation in encouraging their children to participate. Children were assured of confidentiality and were also told that their participation in the interviews was voluntary. The main purpose of the survey was to address the different social networking challenges among school students. This survey was designed to get school student feedback on the uses, impacts, and related aspects of online social networking in Abu Dhabi. The introductory letter explained to students that the policy makers in ADEC urges students to tell them what they do and how they feel about their experiences with online social media and networking. It was also explained that the resulted information will be utilized to improve health and safety education for young people in Abu Dhabi.

The survey started with asking students to provide some personal and school background questions (age, nationality, grade level, gender, etc.). In addition, the survey contained questions about student life aspects both inside and outside the school (i.e., number of close friends, relations with other students outside the school, relations with teachers, etc.). They were asked too to state how their parents were involved in their social networking activities. Students were asked to rate their academic performance (according to the School Report Card) for the last academic year in Arabic, Math, Science, Social Science, English and Arts. Some questions addressed the degree and access to the internet and Wi Fi (at home); and the methods of gaining access. Few questions asked students to tell if they had or were involved in social media networking, and the applications used to access the different options. A question asked students to indicate whether they have an account on online social networking applications (i.e., Facebook, Twitter, LinkedIn, Instagram, YouTube, etc.). A total of 19 choices were provided. A related question asked to identify the sort of applications used (i.e., Watsapp, WeChat, Viper, MS Messenger, etc.). Another question addressed the device used to access online social networking accounts (i.e., Desktop, mobile, laptop, Tablet, etc.). Students were also asked to portray the extent they consider the how important certain reasons were for using online social networking applications. Using a scale ranging from 1 (not important) to 5 (extremely important) eight alternatives were given. For example, "to make friends", or "to keep in touch with family and friends". Using a scale 1 (strongly disagree) to 5 (strongly agree), students were given eleven different items to address. The items addressed student attitude for using social networking. For example, "online social networking keeps me feel connected", "I support using social networking technology for learning in school", and "online social networking increases my understanding of current issues and news". A group of questions addressed behavioral concerns and experiences on social networking. A group if items addressed how often students performed certain things or acts when using online social networking applications. For example, "shared my personal information on my account that is open to the public", or "sent a photo or video of myself to someone that I have never met face-to-face". A group of questions addressed the nature of the topics discussed on social networking. Topics included "ways of physically harming or hurting themselves", "ways of committing suicide", "ways to be very thin", etc. A scale 1 (never) to 5 (always) as used. The last set of items addressed the possibility 
of certain outcomes happened that were directly related to use of social networking. For example, "I have gone without eating or sleeping", "I have spent less time than I should physically with my family and friends", and "I have spent less time than I should doing school work", etc. A scale 1 (never) to 5 (always) was used. The survey took a maximum of $12 \mathrm{~min}$ to complete.

\subsection{Analysis}

Mostly descriptive statistics will be used in the study. To test differences between categories of respondents, both t-tests and analysis of variance (ANOVA) will be utilized. Some correlation analysis is also used to see the degree and direction of association between variables. For the case of categorical variables only, we will use the Chi-square test to determine whether there is a significant association between the two variables (for example use/not use of social networking and gender, or in type of school).

\section{Results}

\subsection{Uses of digital devices and tools}

Out of 31,109 students, $28,517(91.7 \%)$ reported that they have an Internet connection at home. A total of 517 students reported that they did not know if they had an Internet connection at home. A total of 28,202 students (90.6\%) reported having $\mathrm{Wi}-\mathrm{Fi}$ at home. The access to the Internet and Wi-Fi was very high in this sample of students. With regard to devices used to access online social networking accounts, students reported sometimes using multiple methods. Among the various devices, $27 \%$ students used their personal computers, $45.3 \%$ used laptops/notebooks, $49.7 \%$ used tablets (iPad, Samsung Galaxy, Tab, etc.), $63.7 \%$ used mobile phones, $27.4 \%$ used portable media player (iPad Touch, etc.), and $21 \%$ also used other devices.

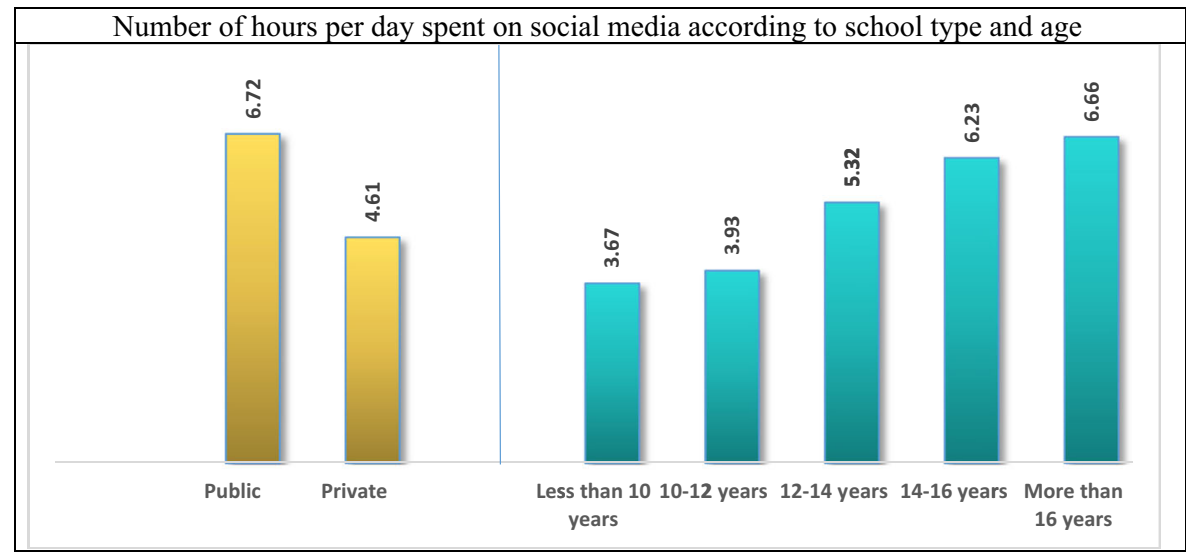

Fig. 1 Number of hours per day spent on social media according to school type and age 


\subsection{Time spent on social networks and perceived student performance}

Students spend an average of $5.2 \mathrm{~h}$ per day on social networking (with a median of $3 \mathrm{~h}$, and mode of $1 \mathrm{~h}$ ). As shown in Fig. 1, the average number of hours per day increases with student age. Students in public schools spend more time on social media than students in private schools. With regard to perceived performance, students were asked to rate their academic performance (according to the School Report Card) for the subjects of Arabic, Math, Science, Social Sciences, and Arts. Results show that there are significant negative correlations between online time and perceived school performance with regard to all subjects.

\subsection{Uses of social networking}

Students were asked if they had an active account or accounts of online social networking applications (i.e., Twitter, MySpace, WhatsApp, etc.). About $81.7 \%$ said they did have accounts. Table 2 shows percentage of students who said "Yes" to the specific application. Students were given 27 different applications to select from. The table only shows those applications for which more than $20 \%$ of the students said they use them. Other applications that were included on the list but which received use by less than $20 \%$ of students included LinkedIn, Pinterest, VK, Flickr, Vine, Meetup, Tagged, Meetme, Classmates, Hi5, Vimeo, Blogger, Frienster, Whisper, Burnchat, Jabble, MySpace, and Piczo. With regard to mobile texting applications, seven choices were provided to select from. The highest usages were related to WhatsApp (86.5\%), Kik messenger (36.3\%), FB messenger (32.3\%), Viber (26.9\%), and MS messenger $(26.5 \%)$.

Students were given seven reasons for why they used social networking applications. The two reasons with the highest means were "To keep in touch with family and friends", and "To find information". The complete responses are shown in Table 3. Since it was expected that some students would report that they did not use social

Table 2 Students using various applications

\begin{tabular}{|c|c|c|c|c|c|c|c|}
\hline \multirow[t]{2}{*}{ Applications } & \multirow[t]{2}{*}{ Percent said (Yes) } & \multicolumn{2}{|l|}{ Gender } & \multicolumn{2}{|c|}{ Type of school } & \multicolumn{2}{|c|}{ Grade differences } \\
\hline & & $\chi^{2}$ & Sig. & $\chi^{2}$ & Sig. & $\chi^{2}$ & Sig. \\
\hline Facebook & $56.9 \%$ & 1454.780 & 0.001 & 1394.536 & 0.001 & 144.156 & 0.001 \\
\hline Twitter & $50.0 \%$ & 155.021 & 0.001 & 345.542 & 0.001 & 1473.424 & 0.001 \\
\hline Google Plus & $54.5 \%$ & 370.036 & 0.001 & 363.599 & 0.001 & 72.749 & 0.001 \\
\hline Tumblr & $25.5 \%$ & 70.821 & 0.001 & 1.421 & 0.233 & 447.418 & 0.001 \\
\hline Instagram & $75.1 \%$ & 1.227 & 0.268 & 479.206 & 0.001 & 776.575 & 0.001 \\
\hline Ask.fm & $25.8 \%$ & 89.559 & 0.001 & 102.214 & 0.001 & 1077.141 & 0.001 \\
\hline Skype & $72.5 \%$ & 12.651 & 0.001 & 16.596 & 0.001 & 284.936 & 0.001 \\
\hline SnapChat & $70.5 \%$ & 0.302 & 0.583 & 793.160 & 0.001 & 743.163 & 0.001 \\
\hline YouTube & $73.9 \%$ & 323.841 & 0.001 & 68.836 & 0.001 & 29.157 & 0.001 \\
\hline
\end{tabular}


Table 3 Student reasons for using social networking (Descriptive stats, and ANOVA)

\begin{tabular}{|c|c|c|c|c|c|c|c|c|}
\hline \multirow[t]{2}{*}{ Items } & \multirow[t]{2}{*}{ Mean } & \multirow[t]{2}{*}{ S.D. } & \multicolumn{2}{|l|}{ Gender } & \multicolumn{2}{|c|}{ Type of school } & \multicolumn{2}{|l|}{ Grade } \\
\hline & & & $\mathrm{F}$ & Sig. & $\mathrm{F}$ & Sig. & $\mathrm{F}$ & Sig. \\
\hline Make new friends & 2.69 & 1.398 & 54.450 & 0.001 & 0.335 & 0.563 & 30.24 & 0.001 \\
\hline Keep in touch with family and friends & 4.08 & 1.153 & 43.366 & 0.001 & 1.447 & 0.229 & 11.49 & 0.001 \\
\hline Share photos/music/videos & 3.03 & 1.374 & 8.342 & 0.004 & 63.10 & 0.001 & 23.06 & 0.001 \\
\hline Play games & 2.92 & 1.469 & 749.99 & 0.001 & 17.90 & 0.001 & 53.85 & 0.001 \\
\hline Find information & 3.78 & 1.267 & 24.762 & 0.001 & 6.184 & 0.013 & 6.88 & 0.001 \\
\hline Assist in learning & 3.60 & 1.327 & 29.107 & 0.001 & 1.355 & 0.244 & 15.13 & 0.001 \\
\hline Most of my friends use it & 3.23 & 1.430 & 49.596 & 0.001 & 78.37 & 0.001 & 6.17 & 0.001 \\
\hline Pass the time & 3.25 & 1.432 & 51.826 & 0.001 & 592.9 & 0.001 & 70.01 & 0.001 \\
\hline
\end{tabular}

networking, it was logical to ask about the reasons. Indeed, $8.3 \%$ of the students reported that they did not use online social media applications. On a scale ranging from 1: Strongly disagree, to 5: Strongly agree, the students were given six reason choices to select from. The highest two reasons were "I am not interested in joining online social networking", and "Face-to-face communication is preferred in my culture".

\subsection{Parents' involvement in children's use of social networking}

Students were asked several questions that were related to parental involvement. The first questions asked students about the person/persons that first told them about social networking applications. The highest percentage $(18.8 \%)$ of the students said that "friends" took the credit. Other choices receiving relatively high scores included "relatives: $17.2 \%$ "; "parents: $15.1 \%$ "; "Internet: $13.5 \%$ "; and "fellow students at school: $7.7 \%$ ".

Students were also asked if their parents were aware of their online social activities. About 82.2 \% said "Yes", $5.8 \%$ said "No", and $12 \%$ said they were "Not Sure". Another question asked if the parents were in the student's friend group on online networking. About $30 \%$ of the students "yes, on all applications", $38.7 \%$ said "yes, on some applications", $23.4 \%$ said "no", and $7.9 \%$ said "not sure".

A final question asked students if, in the case of being a victim of online bullying on social networking, they talked about it to their parents. Only $5.89 \%$ of students said that they were victims of online bullying. From those, $26.4 \%$ said that they talked to their parents about it, while $27.5 \%$ said they talked to a friend, and $22.4 \%$ said that they did not tell anyone. Other choices receiving votes included brother or sister, a teacher, or a social worker at school.

Table 4 shows the student perceived mean school performance in different subjects as they relate with their "parents being aware" of their social activities, and with regard to their "parents being in their social groups". The table also shows the values of the ttest, and the level of significance for those that said "Yes" or "No" to both questions. 
Table 4 Perceived performance in different subjects and parent's involvement in SN activities

\begin{tabular}{|c|c|c|c|c|c|c|c|c|}
\hline & \multicolumn{4}{|c|}{ My parents are aware of my SN } & \multicolumn{4}{|c|}{ Parents in my groups on $\mathrm{SN}$} \\
\hline & \multicolumn{2}{|l|}{ Mean } & \multirow[t]{2}{*}{$\mathrm{t}$} & \multirow[t]{2}{*}{ Sig. } & \multicolumn{2}{|l|}{ Mean } & \multirow[t]{2}{*}{$\mathrm{t}$} & \multirow[t]{2}{*}{ Sig. } \\
\hline & YES & NO & & & YES & NO & & \\
\hline Arabic & 3.90 & 3.75 & 4.158 & .0001 & 4.06 & 3.83 & 11.067 & .0001 \\
\hline English & 3.91 & 3.78 & 3.539 & .0001 & 3.96 & 3.88 & 3.811 & .0001 \\
\hline Math & 3.87 & 3.76 & 3.042 & .0020 & 3.97 & 3.82 & 7.295 & .0001 \\
\hline Science & 4.01 & 3.88 & 3.664 & .0001 & 4.10 & 3.96 & 7.302 & .0001 \\
\hline Social Science & 4.30 & 4.10 & 5.826 & .0001 & 4.34 & 4.29 & 2.864 & .0040 \\
\hline Art & 4.43 & 4.16 & 7.231 & .0001 & 4.45 & 4.44 & 0.304 & .7610 \\
\hline
\end{tabular}

For all subjects (except Art), the perceived performance are higher for those students where parents are more involved with their children in social network applications and activities.

\subsection{Gender differences}

With regard to having or not having a social networking account online and using different devices to access social networking applications, the Chi-square test shows significant association between student gender and using or not using online social networking applications (Pearson Chi-square of 54.888 significant at 0.001 , Phi $=0.043$, significant at 0.001$)$. Percentage of boys having an active online social networking application is more than for girls (85.83\% and $82.64 \%$ respectively).

For those who have online social networking accounts, Chi-square tests were performed with regard to (most used applications) and student gender. Table 1 shows the results. There are significant associations between genders with regard to using most social networking applications. For most applications, boys use them more than girls (Facebook, $71.3 \%$ and $46.3 \%$; Instagram, $75.5 \%$ and $73 \%$; Skype, $74.8 \%$ and $71.7 \%$; YouTube, $80 \%$ and $69.5 \%$, and Google Plus $62.3 \%$ and $49.1 \%$, respectively).

With regard to reasons for using online social networking, analysis variance shows that boys and girls are significantly different on all of the eight reasons given. Full results are shown in Table 4. The table shows the ANOVA F-values and the significant levels. Boys recorded higher means with regard to "to make new friends", "to share photos/music/videos", "to play games", and "most of my friends use it". However, girls recorded higher means with regard to "to keep in touch with family and friends", "to find information", "to assist in learning", and "to pass time".

For those who do not use social networking, significant differences exist between boys and girls for why they do not use online social networking. Full results are shown in Table 6. Boys give higher mean scores to "I don't know what social networking is", and "I joined once before, but I didn't like it". Girls give higher scores to "My parents do not allow me to use it", "I have privacy concerns", and "Face-to-face communication is preferred in my culture". 


\subsection{Grade (or age) differences}

With regard to student grade level, for applications of online social networking, significant differences were observed for all applications. For Facebook, Twitter, Google Plus, and Instagram, an obvious pattern could be noticed. Overall, student usage peaks for Grade 8 to Grade 9 for all four applications. In addition, it gets lower as students' progress to higher grades. For other applications, the usage is almost uniform across all grade levels. For WhatsApp, the highest usage is in Grade 12 (93.6\%) and Grade $11(92.4 \%)$.

Significant differences were observed with regard to all eight reasons for using online social networking. Full results are shown in Table 5. As the grade level (or student age) increases, the mean values for "making new friends", "keeping in touch with family and friends", and "playing games", decreases. For the other five factors, as grade level increases, the mean scores for using online social networking increases too.

For not using online social networking significant differences were observed for the different grades. In general, as students get older, their mean scores for reasons not to use social networking increase for "I am not interested in joining online social networking", and "I have privacy concerns". For other reasons, grade level (or age) has the opposite effect.

\subsection{School type differences}

Chi-Square test shows significant association between public and private school with regard to using online social networking applications (Table 5). In general, the results of the use of applications between private school students and public school students are mixed (Facebook, $37 \%$ and 64.2 \%; Instagram 84.7 \% and 71.2 \%; and Skype, $70.6 \%$ and $73.3 \%$ ) respectively. For WhatsApp, $81.9 \%$ of public and $88.2 \%$ of private schools use it. For MS messenger, $21 \%$ of public and $28.5 \%$ of private schools use it. For Kik messenger, more public schools also use it (49.4\% and $31.1 \%$ respectively).

For school type, analysis of variance shows significant differences with regard to five out of eight issues of reasons for using online social networking. Significant differences

Table 5 Why student do not use social networking

\begin{tabular}{|c|c|c|c|c|c|c|c|c|}
\hline \multirow[t]{2}{*}{ Items } & \multirow[t]{2}{*}{ Mean } & \multirow[t]{2}{*}{ S.D. } & \multicolumn{2}{|c|}{ Gender } & \multicolumn{2}{|c|}{$\begin{array}{l}\text { Type of } \\
\text { school }\end{array}$} & \multicolumn{2}{|l|}{ Grade } \\
\hline & & & $\mathrm{F}$ & Sig. & $\mathrm{F}$ & Sig. & $\mathrm{F}$ & Sig. \\
\hline I don't know what social networking is & 2.19 & 1.293 & 11.33 & 0.001 & 30.40 & 0.001 & 7.712 & 0.001 \\
\hline My parents do not allow me to use it & 2.97 & 1.397 & 8.09 & 0.004 & 11.42 & 0.001 & 6.282 & 0.001 \\
\hline $\begin{array}{l}\text { I am not interested in joining online social } \\
\text { networking }\end{array}$ & 3.10 & 1.404 & 0.078 & 0.780 & 13.17 & 0.001 & 3.885 & 0.001 \\
\hline I have privacy concerns & 2.82 & 1.374 & 4.147 & 0.042 & 10.18 & 0.001 & 4.158 & 0.001 \\
\hline I joined once before, but I didn't like it & 2.34 & 1.344 & 23.30 & 0.001 & 17.32 & 0.001 & 6.302 & 0.001 \\
\hline $\begin{array}{l}\text { Face-to-face communication is preferred in my } \\
\text { culture }\end{array}$ & 3.08 & 1.376 & 4.85 & 0.028 & 1.62 & 0.203 & 1.822 & 0.079 \\
\hline
\end{tabular}


were observed with regard to "sharing photos/music/videos", "to play games", "to find information", "most of my friends use it", and "to pass time". Public school students scored significantly higher means with regard to all those factors except for "playing games" and "to find information", where private school students scored higher means.

Significant differences were observed with regard to all reasons for not using online social networking except for "Face-to-face communication is preferred in my culture", where no significant differences were observed. In general, public school students assigned higher scores to such reasons as "I don't know what social networking is", "I joined once before, but I didn't like it", and "Face-to-face communication is preferred in my culture". For other factors, private school students assigned higher mean scores.

\subsection{Students who experience some sort of cyberbullying and parental involvement}

For students who identified that they were victims of cyberbullying, further analysis was carried out. To be included in the analysis, the students had to select one of two choices, "most of the time", or "always". This condition verified the existence of 1251 cases. For those students, the highest networking applications used were Instagram (82.49 \%), SnapChat (80.5\%), YouTube (79.1\%), and Skype (78.2 \%). The most digital devices used were mobile phones $(87 \%)$, tablets $(76.7 \%)$, and laptops and notebooks $(70.2 \%)$. The most applications used for mobile texting were WhatsApp (90.3\%), Kik Messenger (53.7\%), FB Messenger (43.6 \%), and MS Messenger (43.3\%). The reasons for the highest scores for joining online social networking were calculated by first identifying those students who said that the reason was only "important" or "extremely important". The two highest reasons were identified as "to keep in touch with family and friends" $(65.5 \%)$, and "to find information" $(60.3 \%)$. The per cent was $69.1 \%$ for those who said their parents were aware of their online social networking activities, for not aware it was $14 \%$, and for not sure it was $16.9 \%$. The per cent that said that their where parents were in their friend group list was $31.2 \%$ on all applications, was $30.3 \%$ on some applications, $28.8 \%$ no applications, and $9.7 \%$ were not sure. Most of the students were boys $(54.8 \%)$, belonging mostly to Grade 6 (21.5\%), Grade $9(17.1 \%)$, and Grade 8 (16.5\%), and mostly coming from private schools $(69.1 \%)$. If we take the sample size categorization of public and private schools, then $4.46 \%$ of public schools and $3.84 \%$ of private schools are identified.

It was also important to see if the chances for ever being a victim of online bullying (offensive comments or emails, nasty pictures or videos, etc.) on social networking were influenced (increase or decrease) by parents more being involved in their social networking groups. For students that reported that their parents were aware of their social networking activities, the mean score for ever being a victim of online bullying is 1.71. For students that reported that their parents were not aware of their social networking activities, the mean score for ever being a victim of online bullying is 2.22. The difference is significant ( $t=-13.18$, with level of significance of 0.0001 ).

\section{Discussion}

Access to the Internet and Wi-Fi is relatively high. Out of the five gadgets, more children use mobile phones and tablet PCs. This may be due to their convenience, 
availability and portability. In this sample of Abu Dhabi school students, almost all students have access to the Internet and Wi-Fi at home. Multiple methods are used to access social networking. Students spend on average $5.2 \mathrm{~h}$ every day on online social networking. This number is relatively high if we compare it to similar numbers according to global usage (Ofcom 2014).

Most children prefer using WhatsApp and Kik messenger. They also like using Instagram, YouTube, Skype and SnapChat. Results are a little different with other studies in that students indicated that the websites they preferred the most were Facebook and Twitter (Sheldon 2008; Quan-Haase and Young 2010).

The most important reason cited for using social networking is to keep in touch with family and friends (mean of 4.08). This result is consistent with similar results in other countries (Goh et al. 2015; Ofcom 2012). The other most important reason for using social networking was to find information and assist in learning. In contrast with other global reports (see Internet Society 2015; Goh et al. 2015), playing games was not rated high in Abu Dhabi.

Results show that $8.3 \%$ of the students did not use online social media applications. The main two reasons were related to their lack of interest and preferring face-to-face communication. Barkhuus and Tashiro (2011) recommend that schools and parents should help children understand that social networks could be integrated into their daily lives to help them maintain their pre-existing close relationships, keep in touch with their colleagues and acquaintances through communication and social gatherings tools, and enhance their studying performance.

Table 6 shows that the majority of students said that their parents were aware of their online social networking activities. Only $30 \%$ percent of students said that their parents were in some of their friend-groups (see Table 7). These results are consistent with other studies and reports conducted in other countries (see Doty and Dworkin 2014; Vanderhoven et al. 2014). Similar studies recommend that parents should familiarize themselves with their children so that they can better understand what types of interactions their child is having online, and review their profiles if they are posting personal information such as age, full name, phone number, address, school name or offensive/sexually suggestive photos (Davies and Gentle 2012; Kanthawongsa and Kanthawongs 2013).

Results confirm that for those children who reported that they were subjected to some form of cyberbullying, only $26.4 \%$ said that they talked to their parents about it. From the results, it might be concluded that parents may not be aware or mindful of Internet risks such as cyberbullying or other risks. Some research suggests that lack of

Table 6 Parental connection with children online social networking (awareness)

\begin{tabular}{|c|c|c|c|c|c|c|c|c|c|}
\hline \multirow[t]{2}{*}{ Items } & \multirow[t]{2}{*}{ Yes } & \multirow[t]{2}{*}{ No } & \multirow[t]{2}{*}{$\begin{array}{l}\text { Not } \\
\text { sure }\end{array}$} & \multicolumn{2}{|l|}{ Gender } & \multicolumn{2}{|c|}{$\begin{array}{l}\text { Type of } \\
\text { school }\end{array}$} & \multicolumn{2}{|l|}{ Grade } \\
\hline & & & & $\chi^{2}$ & Sig. & $\chi^{2}$ & Sig. & $\chi^{2}$ & Sig. \\
\hline $\begin{array}{l}\text { Are your parents aware of your } \\
\text { online social networking } \\
\text { activities? }\end{array}$ & $82.3 \%$ & $5.76 \%$ & $11.9 \%$ & 268.88 & 0.001 & 17.44 & 0.001 & 190.4 & 0.001 \\
\hline
\end{tabular}


Table 7 Parental connection with children online social networking (friend group)

\begin{tabular}{|c|c|c|c|c|c|c|c|c|c|c|}
\hline \multirow[t]{2}{*}{ Items } & \multirow[t]{2}{*}{$\begin{array}{l}\text { Yes to } \\
\text { all }\end{array}$} & \multirow[t]{2}{*}{$\begin{array}{l}\text { Yes to } \\
\text { some }\end{array}$} & \multirow[t]{2}{*}{$\begin{array}{l}\text { No to } \\
\text { all }\end{array}$} & \multirow[t]{2}{*}{$\begin{array}{l}\text { Not } \\
\text { sure }\end{array}$} & \multicolumn{2}{|c|}{ Gender } & \multicolumn{2}{|c|}{$\begin{array}{l}\text { Type of } \\
\text { school }\end{array}$} & \multicolumn{2}{|l|}{ Grade } \\
\hline & & & & & $\chi^{2}$ & Sig. & $\chi^{2}$ & Sig. & $\chi^{2}$ & Sig. \\
\hline $\begin{array}{l}\text { Are your parents in your } \\
\text { friend group on online } \\
\text { social networking? }\end{array}$ & $30.0 \%$ & $38.7 \%$ & $23.4 \%$ & $7.75 \%$ & 195.2 & 0.001 & 53.1 & 0.001 & 640.8 & 0.001 \\
\hline
\end{tabular}

rules from parents might cause a challenge in this regard (Goh et al. 2015). It is also possible that parents may have set rules but the children may not have been aware of them as issues of cyber safety may not be so prominent for young children. Other researchers tried to get from parents themselves a more comprehensive picture if they are aware of online risks and if they have consciously set limitations on their children's online use (Love et al. 2016). Many parents use active discussion of online content with their children (Doty and Dworkin 2014).

Results confirm that there are significant negative correlations between online time and perceived school performance with regard to Math, Sciences, Arabic, Social Studies, and Arts. Results are consistent with some studies that reported negative influences with regard to many aspects of student school performance (Rouis et al. 2011; Salvation and Adzharuddin 2014; Rithika and Selvaraj 2013). Such results call for school policy makers to engage in more research to see the tradeoff between the various advantages and disadvantages of using specific social media applications. Such research should help school decision makers to empirically explore significant social networking variables (I.e., time spent, type of applications, etc.) and how they interact with the educational settings and cultures.

Gender, grade level (or age), and school type were significant forces in most of the variables that were addressed. For example, girl social media users are more likely than boys to cite family connections as a major reason for using these sites. The result is consistent with other results in other cultures (Sponcil and Gitimu 2014). Meanwhile, younger children record higher means with regard to this reason.

\section{Implications}

Social networking has soared in importance. Along with mobile use, it has become indispensable and ubiquitous in most children's' lives in Abu Dhabi. Social networking sites play an important role in the lives of children. Over $81.7 \%$ of the students said they have at least one profile on a social networking site. It is alarming to note that many children spend more than $5.2 \mathrm{~h}$ per day on social networking sites. It might be essential for parents to be more involved with children and ask them about their day-today lives with digital devices and social networking applications. Social networking sites can present opportunities to youth who participate with them but like any activity, there are also associated risks and it is important for parents to help their children use these sites wisely. 
Since children cited keeping in touch with family and friends as the reason for using social networking, it is suggested that parents should talk to their children about what they do in their homes, rooms and on the road to the school and back to home. They should also try to envision the kinds of information they might want and need at different times of day and in different places. Parents should encourage their children to talk to them about their ideas on how school work could be part of this lifestyle. Such communication is called for in many related research studies (Wang et al. 2005; Nikken and Jansz 2011; Dodge et al. 2011). Guidance or effective control from parents would reflect on their behavior when using social networking (Haythornthwaite 2005).

These results confirm that social networking and media have become an ingrained part of children's lives today. The children are constantly on Instagram, Facebook, and Twitter. Social networking is bringing the "real world" into the classroom. School policy makers in Abu Dhabi might consider integrating social media into school lessons more seriously and effectively. In Singapore, assistance in learning is also rated highly (Goh et al. 2015). Some teachers noted that online social networking includes much more than Facebook and Twitter; it is any online use of technology to connect students, enable them to collaborate with each other, and form virtual communities.

Parents are encouraged to communicate instructions to their children in clear, simple language to explain what the rules are and what happens if the rules are broken. Parents could also impose time limits allowed for connecting online and using social networks. It is of some concern that some students reported parents do not know about their social networking activities. Goh et al. (2015) suggest that it might be useful to impose specific time limits, for example, this would be $30 \mathrm{~min}$ of play, allowed twice a day, only during the weekends. It is also important for parents to monitor what social networking messages their children get from strangers. Results have confirmed that in many instances some children prefer not to tell their parents.

Results show that parents are sufficiently aware of, and understand the nature of, online risks that their young children can be vulnerable to from the various digital devices and social networking applications available today. It should be also a priority that parents need to be informed of the various risks, and how their children can be exposed to these risks, before they can convincingly develop a set of rules for their children's use of digital devices. Open parent-child communication about all matters related to social networking is encouraged. Children should be convinced that setting rules and open and frank communication are necessary and essential for their growth and safety. Children need to recognize and appreciate the importance of setting priorities so that their usage of digital devices and social networking applications will not interfere with other important commitments such as their school work and homework.

Results affirmed that children in Abu Dhabi spend a lot of time on social networking. The sites they access are the ones most popular worldwide and are a great way for them to interact with friends using mobile devices. Online social networking has changed the way children communicate with their friends and family. Too often though, kids include too much personal information, discuss inappropriate behaviors that could get them into trouble, or otherwise place themselves at risk by what they share online.

Focused interviews or surveys with parents may provide a more comprehensive picture if parents are truly aware of online risks and if they have consciously set limitations on their children's online use. The current results reveal that there are few 
parental instructions with regard to online access. This warrants further investigation if parents are not as conscious as they should be of their children going online. It is important for future research to investigate few significant questions (i.e., how does Abu Dhabi compare with systems where technology use is integrated into school lessons, is there evidence the too much information places students at risk - in Abu Dhabi?, effect of school rule of "No mobile phones at school").

The current study reports on a large scale survey which was answered by school students on voluntary bases. As a result, some observers might question the resulting sample that might not be representative of youth in that country. It should be noted here that many lessons are learned in the current study. Future related studies should encourage all student to participate in the survey. The future survey should also try to cover items related to use of social networking in the class and for school projects and assignments. It might be a good idea too to survey teachers and school leaders to better understand how social networking could benefit school culture and progress.

As a strategic initiative, ADEC might think of the development and promotion of age-appropriate Internet safety education for all age groups in its schools, including pre-primary school or nursery/kindergarten settings. This could also acknowledge the benefits for young children of using Internet enabled devices and social networking, and include digital literacy support and the identification of age-appropriate positive contents and services to enhance online activities. In 2016, policy makers in ADEC designed an e-guide to provide concerned parents with the knowledge to deal with challenges associated with social networking (ADEC 2016). Parents who understand the basics will be better able to help their kids stay safe when they socialize online.

For Abu Dhabi in particular, given the dramatic increase in Internet uptake by young schoolchildren, parents and policymakers have been left without clear direction regarding the benefits and risks involved, and about how best to support children's engagement with the Internet and social networking in safe and beneficial ways. It is to be hoped that the evidence obtained from this study and other research will grow so as to inform the development of relevant policy, support safety education, build public awareness and assist parents in the effective mediation of their young children's Internet use for online activities.

Despite its prevalence in everyday life, ADEC and schools in Abu Dhabi have been hesitant to adopt social networking as an education tool. The teacher's focus group reminded us that schools are one of the "holdouts" as they ban the use of mobiles and the most popular social networking sites for students. ADEC and school administrators justifiably have questions about social networking: How can we protect students? What are the educational benefits? What policy issues need to be considered? There seem to be no quick or easy answers. As a result, the adoption of social networking for education purposes lags behind the student's general usage. Likewise, due to the newness of the phenomenon, empirical research is scarce.

Education policy makers in Abu Dhabi are urged to continue researching the valuable topic of school related social networking. Many questions are worthwhile addressing in this crucial time: "why learning digital competence is important for the society" (e.g. future skills for future jobs, learn variety of ways using such devices to solve problems of tomorrow's society). In this context, some recent research direction from European organizations could offer interesting avenues. For example, the Digital Competence Framework for Citizens (European Commission 2016). It calls for the use 
of devices from the multiple angles (e.g. not only information search and communication, but also the content creation; safety aspects and problem solving in a digitally rich environments). Also, LSE Media and Communication (2016) questions whether ethics of use are of concern. They offer plenty of good work through the network of EU Kids online. These efforts are worthwhile exploring by education policy makers in Abu Dhabi and around the world. In order to develop the academic and policy agendas for researching children's online risks and opportunities, the ADEC policy makers are advised to develop similar strong multidisciplinary research framework to guide the design and conduct of its empirical research and the construction of specific hypotheses for data analysis and policy implications.

\section{Limitations and future research directions}

The sample of private school students that answered the call and participated far exceeds responses from public school students. This result poses some concerns for ADEC. Future student surveys might try other innovative ways to reach more public school students and encourage them to participate.

The results in this study do not make it clear if there are specific rules and time limits with regard to the use of social networking set by parents; and how consistently those rules are applied. Future research might try to seek clearer information. Future research should also try to find out if parents are imposing different rules for different gadgets or applications during different times of the day and in holidays.

Results show that most students use mobile phones and tablets. For policymakers in ADEC, it might be useful to better study the effect of using mobile phones by children. As of the academic year 2016, children are not allowed to bring mobile phones to schools. Perhaps it might be advantageous to better evaluate this decision by better reviewing the benefits of such devices in enhancing learning if properly used at school.

Despite the limitations of this study, results of the interview shed some light on how younger children in Abu Dhabi make use of digital devices and social networking and how much parents are involved in these processes and activities. Future studies are needed to further investigate parental awareness of Internet risks, how these risks may be accessed through the different platforms, and children's responses to parental involvement in their use of the digital devices and social networking.

Open Access This article is distributed under the terms of the Creative Commons Attribution 4.0 International License (http://creativecommons.org/licenses/by/4.0/), which permits unrestricted use, distribution, and reproduction in any medium, provided you give appropriate credit to the original author(s) and the source, provide a link to the Creative Commons license, and indicate if changes were made.

\section{References}

ADEC (Abu Dhabi Education Council). (2016). Parent's guide to social networking. Available from https:/www.adec.ac.ae/en/ResearchDevelopment/ADEC\%20Special\%20Reports/Parent\%E2\%80\%99 s\%20Guide\%20Social\%20Networking_EN.pdf.

Australian Bureau of Statistics. (2012). Children's internet access and mobile phone ownership, selected characteristics: children's participation in cultural and leisure activities, Australia, Apr 2012. Available from http://www.abs.gov.au/websitedbs/D3310114.nsf/home/home?opendocument. 
Barkhuus, L., \& Tashiro, J. (2011). Student socialization in the age of facebook, university of California, San Diego 9500 Gilman Drive, La Jolla, CA 92093, USA, 2010. Available from: http://cseweb.ucsd. edu/barkhuus/barkhuuschi2010.pdf.

Bergin, D. (1993). Patterns of motivation and social behavior associated with microcomputer use of young children. Journal of Education Psychology, 85(3), 437-445.

Brenner, J. (2012). Pew internet: social networking. Retrieved from Pew Internet and American Life Project. http://www.pewinternet.org/Commentary/2012/March/PewInternet-Social-Networking-full-detail.aspx.

Boyd, D. M. \& Ellison, N. B. (2007). Social network sites: Definition, history, and scholarship. Retrieved May 4, 2008. Retrieved from http://jcmc.indiana.edu/vol13/issue1/boyd.ellison.html.

Childwise. (2012). The monitor pre-school report 2012: key behavior patterns among 0 to 4 year olds, Norwich. Reprieved from http://childnetsic.s3.amazonaws.com/downloads/Research_ Highlights/UKCCIS_RH46_Childwise_Monitor_Pre-School_Report_2012.pdf.

Cranmer, S., Selwyn, N., \& Potter, J. (2009). Exploring primary pupils' experiences and understandings of 'esafety'. Education Information Technology, 14, 127-142.

Davies, J., \& Gentle, D. (2012). Responses to children's media use in families with and without siblings: a family development perspective. Family Relationships., 61(3), 410-425.

DeBell, M., \& Chapman, C. (2003). Computer and internet use by children and adolescents in 2001 (statistical analysis report). National Center for education statistics, Washington D.C.

Dodge, A., Husain, N., \& Duke, N. (2011). Connected kids? K-2 children's use and understanding of the internet. Language Arts, 89(2), 86-98.

Doty, J., \& Dworkin, J. (2014). Parents' of adolescent's use of social networking sites. Computers in Human Behavior, 33(April), 349-355.

El Khouli, M. (2013). The most important negative aspects of using social networking affecting the family stability in Abu Dhabi- a pilot study. IACSIT International Journal of Engineering and Technology, 5(1), 85-90.

European Commission. (2016). Being digitally competent - a task for the twenty-first century citizen. Available from https://ec.europa.eu/jrc/en/digcomp/.

Findahl, O. (2012). Swedes and the Internet 2012. Available from https://www.iis.se/docs/Swedes-and-theInternet-2012.pdf.

Global Mideast Insight. (2016). UAE Social Media Statistics 2016 Infographics. Available from http://www. globalmediainsight.com/blog/uae-social-media-statistics/.

Goh, W., Bay, S., \& Chen, V. (2015). Young school children's use of digital devices and parental rules. Telematics and Informatics, 32(2015), 787-795.

Greenfield, P., \& Yan, Z. (2006). Children, adolescents, and the internet: a new field of inquiry in developmental psychology. Developmental Psychology, 42, 391-394.

Gross, E. (2004). Adolescent internet use: what we expect, what teens report? Applied Developmental Psychology, 25, 633-649.

Haythornthwaite, C. (2005). Social networks and internet connectivity effects. Journal of Information, Communication, and Society, 8(2), 125-147.

Heft, T., \& Swaminathan, S. (2002). The effects of computer on the social behavior of preschoolers. J. Res. Child. Educ. 16 (2), Available from http://www.freepatentsonline.com/article/Journal-Research-inChildhood-Education/86875099.html.

Henderson, R. (2011). Classroom pedagogies, digital literacies and the home-school digital divide. International Journal of Pedagogies Learning, 6(2), 152-161.

Holloway, D., Green, L., \& Livingstone, S. (2013). Zero to eight. Young children and their internet use. EU Kids Online, LSE, London.

InfoComm Development Authority of Singapore. (2010). Infocomm Usage - Households and Individuals. Available from http://www.ida.gov.sg/Infocomm-Landscape/Facts-and-Figures/Infocomm-UsageHouseholds-and-Individuals\#4.

Internet Society. (2015). Internet society global internet report. Available from http://www.internetsociety. org/globalinternetreport/assets/download/IS_web.pdf.

Kanthawongsa, P., \& Kanthawongs, P. (2013). Perception of primary school students, parents and teachers toward the use of computers, the internet and social networking sites. Procedia - Social and Behavioral Sciences, 88, 282-290.

Karpinski, A., Kirschner, P., Ozer, L., Mellott, J., \& Ochwo, P. (2013). An exploration of social networking site use, multitasking, and academic performance among United States and European university students. Computers in Human Behavior, 29(2013), 1182-1192.

Kirschner, P., \& Karpinski, A. (2010). Facebook and academic performance. Computers in Human Behavior, 26, 1237-1245. 
Lenhart, A. \& Madden, M. (2007). Social networking websites and teens. Pew Internet and American Life Project. http://www.pewinternet.org/media//Files/Reports/2007/PIP_SNS_Data_Memo_Jan_2007.pdf.

Lenhart, A., Purcell, K., Smith, A. \& Zickuhr, K. (2010). Social media and mobile Internet use among teens and young adults. Pew Internet and American Life Project. Retrieved from http://pewinternet. org//media//Files/Reports/2010/PIP_Social_Media_and_Young_Adults_Report_Final_with_toplines.pdf.

Lenhart, A. (2012). Teens and video. Pew Internet and American Life Project. Retrieved from http://pewinternet.org/Reports/2012/Teens-and-online-video/Findings.aspx?view=all.

Lenhart, A., Smith, A.., Anderson, M., Duggan, M., \& Perrin, A. (2015). "Teens, Technology and Friendships." DC: Pew Research Center.

Liau, A., Khoo, A., \& Ang, P. (2005). Factors influencing adolescent's engagement in risky internet behavior. International Journal of Cyber Behavior Psychology, 8(2), 513-520.

Livingstone, S., \& Haddon, L. (2008). Risky experiences for children online. Child and Society Journal, 22, 314-323.

Love, S., Sanders, M., Turner, K., Maurange, M., Knott, T., Prinz, R., Metzler, C., \& Ainswortha, A. (2016). Social media and gamification: Engaging vulnerable parents in an online evidence-based parenting program. Child Abuse \& Neglect (forthcoming). Accessed from https://www.csun. edu/sites/default/files/Love\%20et\%20al.\%20(2016).\%20Social\%20Media\%20and\%20gamification.pdf.

LSE Media and Communications. (2016). EU Kids Online. ASignificant differences were observed with vailable from http://www.lse.ac.uk/media@1se/research/EUKidsOnline/EU\%20Kids\%20Online\%20reports.aspx.

Mythily, S., Qiu, S., \& Winslow, M. (2008). Prevalence and correlates of excessive internet use among youth in Singapore. Annals of the Academy of Medicine Singapore, 37, 9-14.

Nikken, P., \& Jansz, J. (2011). Parental mediation of young children's internet use. Paper Presented at the EU Kids Online Conference, London. Available from http://www2.1se.ac. uk/media@1se/research/EUKidsOnline/Conference\%202011/Nikken.pdf.

O'Keeffe, G., \& Clarke-Pearson, K. (2011). Clinical report - the impact of social media on children, adolescents and families. American Academy of Pediatrics, 800-804.

Ofcom. (2012). Children and parents: media use and attitudes report. London. Available from http://stakeholders.ofcom.org.uk/binaries/research/medialiteracy/oct2012/main.pdf.

Ofcom. (2014). Children and Parents: Media Use and Attitudes Report. Available from http:/stakeholders. ofcom.org.uk/binaries/research/media-literacy/media-use-attitudes-14/Childrens_2014_Report.pdf.

Paul, J., Baker, H., \& Cochran, J. (2012). Effect of online social networking on student academic performance. Journal of Computers in Human Behavior, 28(6), 2117-2127.

Pew Internet and American Life Project. (2002). The Digital Disconnect: The Widening Gap between Internet Savvy Students and their Schools. Available from http://www.pewinternet.org.

Pew Internet and American Life Project (2011). Trend data. http://pewinternet.org/Trend-Data-(Teens)/OnlineActivites-Total.aspx.

Quan-Haase, A., \& Young, A. L. (2010). Uses and gratifications of social media: a comparison of facebook and instant messaging. Bulletin of Science, Technology \& Society, 30(5), 350-361. doi: $10.1177 / 0270467610380009$.

Rideout, V. J., Foehr, U. G., \& Roberts D. F (2010). Generation M: media in the lives of 8-to 18- year olds. Henry J. Kaiser Family Foundation. Retrieved from http:/www.eric.ed.gov/PDFS/ED527859.pdf.

Rithika, M., \& Selvaraj, S. (2013). Impact of social media on students' academic performance. International Journal of Logistics and Supply Chain Management Perspective, 2(4), 636-640.

Roberts, D., Foehr, U., \& Rideout, V. (2005). Generation M: Media in the Lives of 8-J8 Year Olds. Kaiser Family Foundations (Publication 7251). Available from http://www.kft.org/entmedia/7251.1.

Rosen, L., Lim, A., Felt, J., Carrier, L., Cheever, N., Lara-Ruiz, J., Mendoza, J., \& Rokkum, J. (2014). Media and technology use predicts ill-being among children, preteens and teenagers independent of the negative health impacts of exercise and eating habits. Computers in Human Behavior, 35, 364-375.

Rouis, S., Limayem, M., \& Salehi-Sangari, E. (2011). Impact of Facebook usage on students' academic achievement: role of self-regulation and trust. Electronic Journal of Research in Educational Psychology, 9(3), 961-994.

Salvation, M., \& Adzharuddin, N. A. (2014). The Influence of Social Network Sites (SNS) upon Academic Performance of Malaysian Students. International Journal of Humanities and Social Sciences, 4(10), $131-137$.

Sheldon, P. (2008). Student favorite: Facebook and motives for its use. Southwestern Mass Communication Journal, 23(2), 39-53.

Shields, M., \& Behrman, R. (2000). Children and computer technology: analysis and recommendations. The Future of Children, 10(2), 4-30. 
Sponcil, M., \& Gitimu, P. (2014). Use of social media by college students: relationship to communication and selfconcept. Journal of technology research. Available from: http:/www.aabri.com/manuscripts/121214.pdf.

Subrahmanyam, K., Kraut, R., Greenfield, P., \& Gross, E. (2000). The impact of home computer use on children's activities and development. The Future of Children, 10(2), 123-144.

Teuwen, J., De Groff, D., \& Zaman, B. (2012). Flemish preschoolers online: a mixed-method approach to explore online use, preferences and the role of parents and siblings. Paper presented at the Etmaal van de Communicatiewetenschap, Leuven, Belgium. Available from https://irias.kuleuven. be/bitstream/123456789/350708/1/Flemish+Preschoolers+Online_English+version.pdf.

Turow, J. (1999). The internet and the family: the view from the parents, the view from the press. Annenberg Public Policy Center, University of Pennsylvania, Philadelphia.

Vanderhoven, E., Schellens, T., Valcke, M., \& De Koning, E. (2014). Involving parents in school programs about safety on social network sites. Procedia - Social and Behavioral Sciences, 112(February), 428-436.

Wang, R., Bianchi, S., \& Raley, S. (2005). Teenagers' internet use and family rules: a research note. Journal of Marriage and Family, 67, 1249-1258.

Willett, R. (2015). The discursive construction of 'good parenting' and digital media - the case of children's virtual world games. Media, Culture \& Society, 37(7), 1060-1075.

Wilson, B., Martins, N., \& Marske, A. (2005). Children's and parents' fright reactions to kidnapping stories in the news. Communication Monographs, 72(1), 46-70.

Yan, Z. (2005). Age differences in children's understanding of the complexity of the internet. Applied Developmental Psychology, 26, 385-396.

Yelland, N. (1994). Cooperative learning in a computer context. Paper presented at the meeting of the Asia Pacific information Technology in Training and Education Conference and exhibition, Brisbane, Australia. 